\title{
Maternal anxiety and family support among mothers of neonates admitted in Neonatal Intensive Care Unit
}

\author{
Binu Margaret $E^{1}$, Sheela Shetty ${ }^{1}$, Leslie Edward Lewis ${ }^{2}$, Ramesh Bhat $\mathrm{Y}^{2}$ \\ ${ }^{1}$ Assistant Professor, Department of Child Health Nursing, Manipal College of Nursing, Manipal, Manipal \\ University, India \\ ${ }^{2}$ Professor, Department of Pediatrics, Kasturba Medical College, Manipal, Manipal University, India
}

\begin{abstract}
:
Background: Birth of a newborn requiring admission to NICU represents traumatic experience for some parents.
\end{abstract}

Objective: The present study aimed to determine the maternal anxiety and family support experienced by mothers of neonates admitted in NICU and to find the relationship between them.

Materials and methods: A survey approach using descriptive correlative survey design was adopted for the study. Data was collected from 20 mothers of neonates admitted in NICU of Kasturba Hospital, Manipal using purposive sampling. The data collection instruments include: Demographic Proforma, State Trait Anxiety Inventory (STAI), Family Support Scale

Results: Findings of the study revealed that majority $65 \%$ of mothers had state anxiety whereas $80 \%$ had trait anxiety. Mean state anxiety was $52.55 \pm 18.15$, trait anxiety was $53.55 \pm 14.46$. Majority $80 \%$ of mothers had high family support. $(M=38.4 \pm 8.8)$. Maternal state anxiety $(\rho=-0.655, p<0.05)$ and maternal trait anxiety $(\rho=$ $-0.638, p<0.05)$ with family support was negatively correlated and it is inferred that as family support increases there will be decrease in the anxiety level of mothers.

Conclusion: Mothers exhibit high levels of anxiety during their neonate's hospitalization. Early identification of anxiety level has implications for support of mothers during hospitalization of their newborns.

Keywords: Family support, maternal anxiety, mothers, neonates, NICU

\section{Introduction}

The birth of a newborn requiring admission to a Neonatal Intensive Care Unit (NICU) can represent a traumatic experience for the parents. The neonates require specialized medical care in the NICU due to the conditions of organic instability in the infants. Due to this, the family experiences separation from their neonates and have uncertainty about the survival and the later clinical outcomes. The neonatal intensive care unit environment also has the potential to exacerbate the anxiety of mothers of neonates admitted to the NICU.

In a study conducted among parents whose neonates are hospitalized in NICU showed high levels of anxiety, depression and hostility which also revealed problems of psychosocial adjustment of the parents. (1) About $50 \%$ of mothers of premature infants have elevated levels of anxiety symptoms during hospitalization. (2) Maternal anxiety can have deleterious effects on mother-infant interaction, particularly on mothers' abilities to form an attachment to their baby Maternal anxiety was significantly $(\mathrm{p}<0.05)$ related to the infants' gender and duration of hospitalization. (3)

Family support is a key factor in which mothers get support during the stay of their neonate in the NICU. Family's ability to adjust or the capability to perform changes within the family system when facing a distressing event, is related to the family's internal and social resources. This helps to keep the families equilibrium and functioning and adopt strategies to face up with the situation during the hospitalization of the infant in the NICU.(4) Mothers, in turn, have higher levels of anxiety than fathers. $(5,6)$

This situation creates a need for practices that support parents during the acute phase of their infant's hospitalization in neonatal intensive care. (7) The facilitation of maternal confidence and positive parenting in the NICU may be a key point in establishing and sustaining long-term healthy mother-infant interactions and positive child outcomes. (8) Nurses can play a vital role in facilitating by assisting mothers of babies in the NICU to cope with the experience through exploration of the psychological aspects of the mother and by encouraging the family members about the need for the family support during the stay in the hospital.

The current study was carried out to assess the level of anxiety and the family support received by the mothers of neonates who are hospitalized in NICU. The study also explores whether the family support received by the mothers of neonates admitted in the NICU has an effect on the levels of anxiety. The study will provide a baseline data to plan further interventions for the mothers by the health professionals and to facilitate adaptation 
and coping of the mother, thereby promoting optimal mother-infant relationships and subsequent infant development.

\section{Materials and Methods}

The study was conducted among the mothers whose neonates were admitted in the Neonatal Intensive Care Unit (NICU) of a tertiary level hospital using descriptive correlative survey design. Purposive sampling technique was used to select the 20 mothers whose neonates were admitted in the NICU. The data was collected using interview method.

\subsection{Measures}

The instruments used to collect the data were: Demographic proforma, State Trait Anxiety Inventory (STAI) and Family Support Scale.

\section{Tool 1: Demographic proforma}

The demographic proforma was designed to collect the background information of the participants under the study.

\section{Tool 2: State Trait Anxiety Inventory (STAI)}

Level of anxiety was measured by using the State Trait Anxiety Inventory. The STAI is a validated 20 item self report assessment device which includes separate measures of state and trait anxiety, constructed by Charles D. Spielberger, Richard L. Gorsuch, and Robert E. Lushene in 1964. The scale's first 20 items measure state anxiety by asking subjects how they feel "right now". Subjects rate their feelings on a four point intensity scale. The next 20 items measure trait anxiety by asking subjects how they "generally" feel. Subjects rate themselves on a four point frequency scale and those who score more than 40 in each scale is considered to be anxious. For the Trait-anxiety scale the reliability coefficients ranged from .65 to .86 , whereas the range for the State-anxiety scale was .16 to .62 the alpha coefficients for the state anxiety scale are 0.90 and higher.

\subsection{Family Support Scale}

Family support scale measures the support given by the family members in the form of emotional support, instrumental support and informational support. The scale had 15 items in a three point scale with maximum score of 45 and a minimum score of 15 . There were three responses for each item and their scores were given respectively.ie, never- 1 ; sometimes-2; always- 3 . The scoring is arbitrarily classified as: Low family support (15-24); Moderate family support (25-35); High family support (36- 45). The reliability was calculated by cronbach's alpha and the internal consistency of the tool was 0.9 .

\subsection{Data Collection Procedure}

After obtaining administrative permissions from the concerned authority, data was collected from 20 mothers of neonates admitted in NICU of Kasturba Hospital, Manipal by structured interview method. Before collecting the data, the researcher introduced herself, explained the purpose of the study and written consent was taken. The subjects were assured about the confidentiality of the responses provided. Institutional Ethical Clearance was also taken.

\section{Results}

The data gathered was coded and entered in master data sheet. SPSS 16 was used to analyse the data. The data was analysed based on the objectives of the study.

\subsection{Description of sample characteristics}

The sample characteristics of 20 mothers whose neonates were admitted in the NICU is described in Table 1. The data revealed that: Most (40\%) of mothers belonged to the age group of $20-25$ years, $35 \%$ in $26-$ 30 yrs and $25 \%$ belong to $31-35$ years. Majority $(80 \%)$ of the mothers were primiparous, Hindu middle class joint family and $90 \%$ of them were housewives. The education level of $35 \%$ of mothers was higher secondary and $30 \%$ had high school education. The gestational age of most (40\%) of mothers was $31-34$ weeks, while $35 \%$ had less than 30 weeks gestation. Sixty percent of neonates were males. Most of them (55\%) had a birth weight of 1501 to 2500 grams, whereas $35 \%$ had less than 1500 grams. The length of stay in NICU for $40 \%$ of neonates was more than 15 days. Almost all mothers (95\%) expressed their need for support and $85 \%$ of them were supported by their close family members i.e., mothers. None of the mothers had previous experience of having any child admitted in NICU. 


\subsection{Description of level of anxiety and family support}

The level of anxiety among mothers whose neonates were admitted in NICU was measured by State Trait Anxiety Inventory and the family support was measured using Family Support Scale. The data shows that the State anxiety was found among $65 \%$ of mothers whereas $80 \%$ of them had trait anxiety. The mean state anxiety score was $52.55 \pm 18.15$ and the mean trait anxiety score was $53.55 \pm 14.46$.

Majority $(80 \%)$ of the mothers had high family support, $5 \%$ had moderate family support whereas $15 \%$ of them had low family support. The mean score for family support was $38.4 \pm 8.8$.

\subsection{Relationship between maternal anxiety and family support}

The relationship between maternal anxiety and family support was measured using correlation coefficient. Maternal state anxiety $(\rho=-0.655, p<0.05)$ and maternal trait anxiety $(\rho=-0.638, p<0.05)$ with family support was negatively correlated and it was inferred that as family support increases there will be decrease in the anxiety level of mothers.

\section{Discussion}

The present study findings showed that the state anxiety level was found to be $65 \%$ in the mothers whose neonates were hospitalized whereas the trait anxiety among mothers was $80 \%$. A study conducted by Padovani FH etal. also showed that the preterm infant's mothers presented situational anxiety level of $35 \%$ during hospitalization (1) which supports the present study findings. In another study performed with parents of premature babies with bronchodysplasia it was observed that anxiety-state levels decreased significantly after the infant's hospital discharge. (6) Maternal anxiety in the NICU was found to be a significant and independent predictor of child cognitive development and internalizing behavior problems, controlling for maternal education and neonatal morbidity. (10)

The findings of the present study revealed that as family support increases there will be decrease in the anxiety level of mothers. A study conducted among mothers of stillborn babies showed that mothers who perceived family support in the period after stillbirth experienced lower levels of anxiety than those of their counterparts which is congruent with the study findings. (11) Another study conducted by Doering LV also showed that lower levels of social support, was associated with higher levels of anxiety which supports the present study findings. (5)

Nurses should actively involve in early identifying the anxiety among the mothers and support the mothers to prevent further complications. They should also encourage the family members to support the mothers during the stay of their neonates in NICU. Early identification of anxious mothers of neonates is indicated to promote optimal developmental outcomes.

Table 1: Frequency and Percentage distribution of sample characteristics:

\begin{tabular}{|c|c|c|}
\hline Sample characteristics & Frequency & Percentage \\
\hline $\begin{array}{l}\text { Age of the child in days } \\
1-15 \\
-\quad 16-30 \\
\text { - } \\
31-45\end{array}$ & $\begin{array}{l}8 \\
9 \\
3\end{array}$ & $\begin{array}{l}40 \\
45 \\
15\end{array}$ \\
\hline $\begin{array}{ll}\text { Gender } & \\
\bullet & \text { Male } \\
\bullet & \text { Female }\end{array}$ & $\begin{array}{c}12 \\
8\end{array}$ & $\begin{array}{l}60 \\
40\end{array}$ \\
\hline $\begin{array}{lc}\text { Birth weight (gms) } \\
\text { - } \\
\text { - } \\
\text { - } \\
150-1500 \\
2501-3500 \\
\end{array}$ & $\begin{array}{c}7 \\
11 \\
2\end{array}$ & $\begin{array}{l}35 \\
55 \\
10\end{array}$ \\
\hline \begin{tabular}{ll}
\multicolumn{2}{l}{ Gestational age (weeks) } \\
$\bullet$ & $<30$ \\
- & $31-34$ \\
- & $35-37$ \\
- & $38-42$
\end{tabular} & $\begin{array}{l}7 \\
8 \\
2 \\
3\end{array}$ & $\begin{array}{c}35 \\
40 \\
10 \\
15\end{array}$ \\
\hline $\begin{array}{ll}\text { Days of NICU stay } \\
\text { - } & 1-5 \\
: & 6-10 \\
\bullet & 11-15 \\
- & \text { More than } 15\end{array}$ & $\begin{array}{l}5 \\
4 \\
3 \\
8\end{array}$ & $\begin{array}{l}25 \\
20 \\
15 \\
40\end{array}$ \\
\hline $\begin{array}{ll}\text { Gravida } & \\
\bullet & \text { Primi } \\
- & \text { Second } \\
- & \text { Third }\end{array}$ & $\begin{array}{l}16 \\
3 \\
1\end{array}$ & $\begin{array}{c}80 \\
15 \\
5\end{array}$ \\
\hline
\end{tabular}




\begin{tabular}{|c|c|c|}
\hline $\begin{array}{ll}\text { Educational status of mother } \\
\text { - } & \text { Illiterate } \\
\text { - } & \text { Upper primary }\left(5^{\text {th }}-7^{\text {th }}\right) \\
\text { - } & \text { High school }\left(8^{\text {th }}-10^{\text {th }}\right) \\
\text { - } & \text { Higher secondary } \\
\text { - } & \text { Graduate }\end{array}$ & $\begin{array}{l}1 \\
1 \\
6 \\
7 \\
5\end{array}$ & $\begin{array}{c}5 \\
5 \\
30 \\
35 \\
25\end{array}$ \\
\hline
\end{tabular}

\section{Conclusion}

The birth and subsequent hospitalization of a neonate evokes considerable psychological distress in mothers. The study findings conclude that mothers whose neonates are admitted in NICU exhibit high levels of anxiety during their neonate's hospitalization. Maternal anxiety in the NICU predicted to have adverse interactive behaviors when the children are 24 months corrected age. (9) Early identification of anxious mothers in the NICU is needed in order to initiate preventive intervention to support the mother-infant relationship

Also early identification of anxiety level in the mothers has implications for the support of mothers during hospitalization of their newborns. These results have implications for policy development in order to enhance family centered care and family support groups in the neonatal intensive care.

\section{References}

[1]. F. H. P. Padovani, M. B. M. Linhares, A. E. V. Carvalho, G. Duarted and F. E. Martineze, Anxiety and depression symptoms assessment in pre-term neonates' mothers during and after hospitalization in neonatal intensive care unit. Rev Bras Psiquiatr, 26(4), 2004, 251-4.

[2]. D.A Davis, M.S Miles, M.A Weaver, D. Black, B. Linda, S. Thoyre and E. Stephen. Patterns of Distress in African American Mothers of Preterm Infants, J Dev Behav Pediatr, 30 (3), 2009 June, 193-205.

[3]. Y Erdem. Anxiety levels of mothers whose infants have been cared for in unit level-I of a neonatal intensive care unit in Turkey, Journal of Clinical Nursing, 19(11-12), 2010 June, 738-1747.

[4]. J Pinelli, Effects of family coping and resources on family adjustment and parental stress in the acute phase of the NICU experience, Neonatal Netw, 19(6), 2000, 27-37.

[5]. LV Doering, DK Moser, K Dracup, Correlates of anxiety, hostility,depression, and psychosocial adjustment in parents of NICU infants, Neonatal Netw, 19(5), 2000, 15-23.

[6]. V Zanardo, F Freato, Home oxygen therapy in infants with bronchopulmonary dysplasia: assessment of parental anxiety, Early Hum Dev, 65(1), 2001, 39-46

[7]. K Sloan, J Rowe, L Jones, Stress and coping in fathers following the birth of a preterm infant, J Neonatal Nurs, 14, 2008, 108-15.

[8]. BM Melnyk, L Alpert-Gillis, NF Feinstein, E Fairbanks, J Schultz-Czarniak, D Hust, et al, Improving cognitive development of low-birth-weight premature infants with the COPE program: A pilot study of the benefit of early NICU intervention with mothers. Res Nurs Health. 2001;24:373-89

[9]. P Zelkowitz, A Papageorgiou, C Bardin, T Wang, Persistent maternal anxiety affects the interaction between mothers and their very low birthweight children at 24 months, Early Human Development, 85 (1), January 2009, 51-58.

[10]. P Zelkowitz, S Na, T Wang, C Bardin, A Papageorgiou, Early maternal anxiety predicts cognitive and behavioural outcomes of VLBW children at 24 months corrected age, Acta Paediatrica, .May 2011, 700-704.

[11]. Cacciatore J, Schnebly S, Froen JF, The effects of social support on maternal anxiety and depression after stillbirth. Health Soc Care Community,17(2), 2009 Mar, 167-76. 